\title{
Role of Aerosol laden precipitation from West Asia and hot-humid air from Bay Of Bengal in development of thunderstorm situation in NE part of India: A brief report
}

\author{
M. Devi ${ }^{1 *}$, M. Saikia ${ }^{1}$ Y. Zahan ${ }^{1}$ and A. K. Barbara ${ }^{1}$ and W. Chen ${ }^{2}$ \\ ${ }^{I}$ Department of Physics, Gauhati University, Assam, India \\ *Email:md555gu@gmail.com
}

\begin{abstract}
Thunderstorm being one of the deadliest hazards of the North East (NE) part of India an attempt is made, in this brief report to identify the sources of precipitation which act as one of the main controlling forces in triggering these events. Starting with seasonal occurrence preference of thunder activity over the study zone, the report highlights all possible sources associated with the generation of precipitation of the zone. Out of three windows through which humid air enters this region, the paper shows that most effective windows in this regards are west one through which aerosol laden precipitation from flows to the region along the Sub Himalayan terrain and the other effective window is in the south west, carrying hot humid air from Bay of Bengal. Utilizing Aerosol Optical Depth (AOD) parameter from MODIS and aerosol backscattering / extinction coefficient from LIDAR of Guwahati and precipitation data from satellite, the paper presents that aerosol entering through west China is one of the sources for the growth of suitable Cloud Condensation Nuclei during vernal equinoxial months a season that favors development of thunderstorm, in presence of warm humid air parcel from Bay Of Bengal (BOB). However the relevant other parameters like vertical shear, magnitude of CAPE of lower troposphere, are not dealt here and will be taken up for analysis as future course of study.
\end{abstract}

Key words: 1: Thunderstorm, 2: Sub-Himalayan, 3: Precipitation surces, 4: Aerosol optical depth

\section{5: Cloud condensation nuclei}

\section{Introduction}

Thunderstorm-induced effects are diverse in nature and their manifestations are observed right from the surface of the earth to thousands of $\mathrm{km}$ up in the atmosphere. Conventional monitoring of meteorological parameters [Lung et al., 2003] such as temperature, pressure, wind shear, wind direction etc., are now largely utilized for uncovering developement scenario of Thunderstorm [Yamane et al., 2006; Mukhopadhyay et al., 2003; Sen et al., 1931; Aspliden et al., 1976; Chaudhari et al., 2010; 
Kessler, 1982; Markowski et al., 2002; Chaudhari et al, 2009; Koteswaram and Srinivasan, 1958]. However, understanding on the dynamical and physical aspects of tropical and subtropical thunderstorms [Betts, 1974; Kumar et al., 2006] is still not adequate for providing reliable nowcasting compared to the knowledge of mid and high latitude thunder events. The earlier reports [Manohar et al., 1999; Tyagi, 2007] also suggest that thunderstorm characters differ in this region compared to high, mid and equatorial regions. Therefore, special efforts need to be given for understanding atmospheric status and sources of generation of thunder events over subtropical region so that possible precursory feature may be adopted. In this context, it is worth mentioning that the casualty caused by thunder is far high compared to those caused by other natural hazards in India. The study shows that number of deaths by lightning is more than two times even compared to that caused by next hazardous phenomenon like flood (Figure 1). It is equally important to understand the contribution of orographic conditions of a region in development of thunder and lightning, where NE part of India has a special zonal characteristics compared to rest of the Subcontinent [Das, 2015]. Under this background the paper presents a few potential precipitating sources that may lead to thunderstorm at the NE environment.

For this purpose, satellite rain data, Radiosonde observations from India Meteorological Department, Aerosol Optical Depth (AOD) from MODIS and aerosol backscatter and extinction coefficient from Lidar of Gauhati University will be utilized.

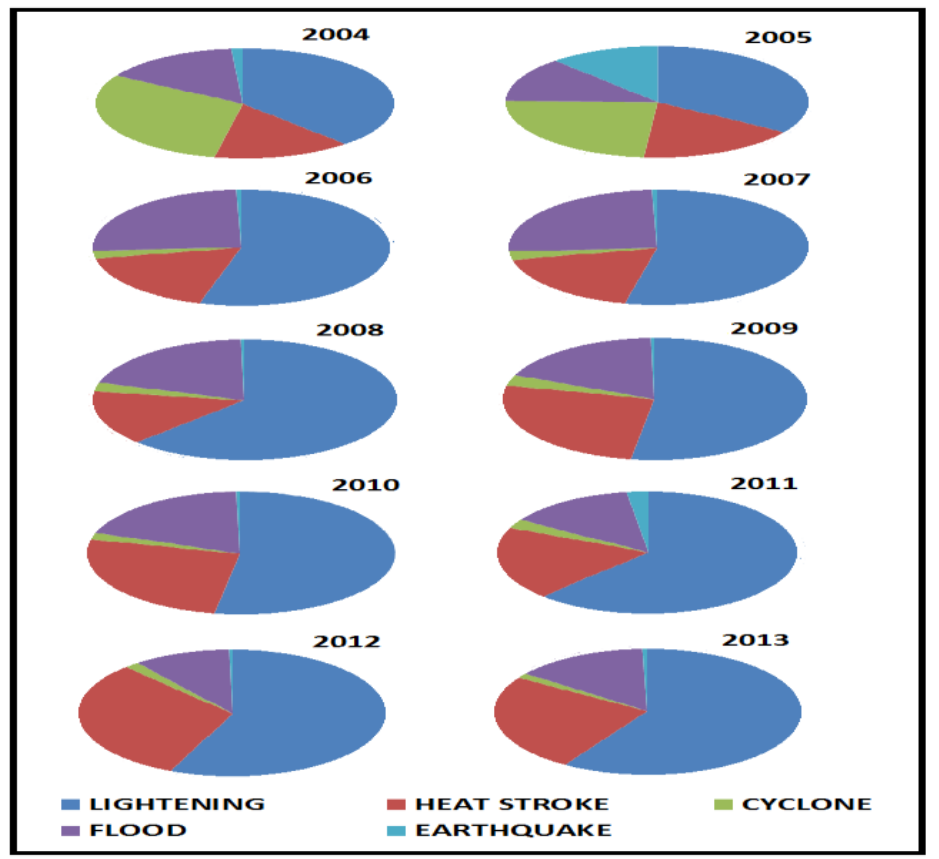

Figure 1. Causalities caused by different natural hazard over India 


\subsection{Thunderstorm : the basic inputs of its development}

For growth of a thunderstorm the necessary conditions are: (i) the background environment should have sufficient temperature, (ii) plenty of moister from lower to midlevel of the troposphere be available and (iii) atmosphere be conducive for generation of instability. Amongsts all these three conditions, it is important to know the first two status of the atmosphere because these situations dictate the process of development of instability. Such conditions then trigger thunderstorms mainly through potential instability generated when dry air overlies a moist warm air accompanied by up-drifting of air. The rising saturated air parcel then gets diluted by mixing with relatively dry environment at higher altitude. This process will generate instability as heavy dry air has to be supported by lighter one under the force of gravity. The instability will then grow as the heavier material moves down under the gravitational field, and the lighter material is displaced upwards. This process releases potential energy, thus more energy is available for storm activities. With the growth of the instability, the downward-moving irregularities get magnified creating favourable situation for development of storm. Therefore, for generation of thunderstorm the essential requirements are the presence of warm humid air parcel and that has to move sufficiently high to create storm cell.

Another essential requirement is presence of aerosol of special form as its role in formation or inhibition of rain bearing cloud through formation of Cloud Condensation Nuclei (CCN) is significant. It has been well reported [Twomey, 1959; Lee et al 2015], that high CCN concentration, decreases the Cloud drop number concentration (CDNC) by increasing the effective radius. Such status may lead to increase surface precipitation. But for low CCN concentrations, there are respective changes in CDNC and mean effective radius may lead to decrease in the surface precipitation. It is thus important to know the role of aerosol in growth of $\mathrm{CCN}$ as a trigger source in development of thunder event.

Under these backgrounds two basic possible sources that may be relevant for triggering thunderstorm at NE region will be examined.These are (i) hot- humid air flow sources to the region leading to thunder associated precipitation and (ii) potential aerosol generating roots leading to formation of $\mathrm{CCN}$, a component for formation of storm cloud. These two aspects being influenced by seasonal changes in the environment, we will first examine seasonal thunderstorm occurrence pattern over Guwahati i.e., to identify the thunderstorm season over the region of study. 


\section{Analysis: Thunderstorm: Seasonal Character over Guwahati;}

Thunderstorm over Guwahati is basically a vernal equinoxial phenomenon (Figure 2a, April to May), though there may be thunderstorm events during summer and autumnal seasons ( Figure 2b). This feature is reflected in the long period of study of thunderstorm events and presented in Figure 3, for eight years of observations covering 2008 to 2015. For this purpose, the daily thunderstorm events are analysed for deriving the mean value of a month and then three months of average are calculated to estimate the occurrence character at three different seasons of a year i.e. vernal equinox (March-Mid May), monsoon (June to August) and post monsoon (August-October ) seasons. A clear increase in thunder activities during vernal equinoxial months is significantly noted.
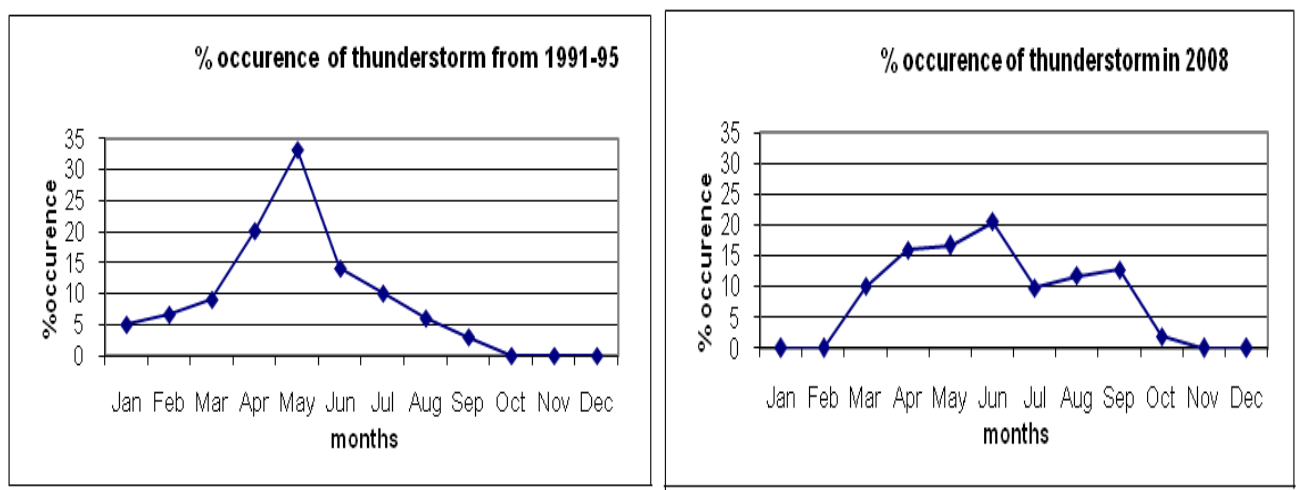

Figure 2: thunderstorm occurrence percentage (a) Strong single peak during vernal equinoxial months (b) High activities in vernal equinoxial months spread to autumnal season with less events.

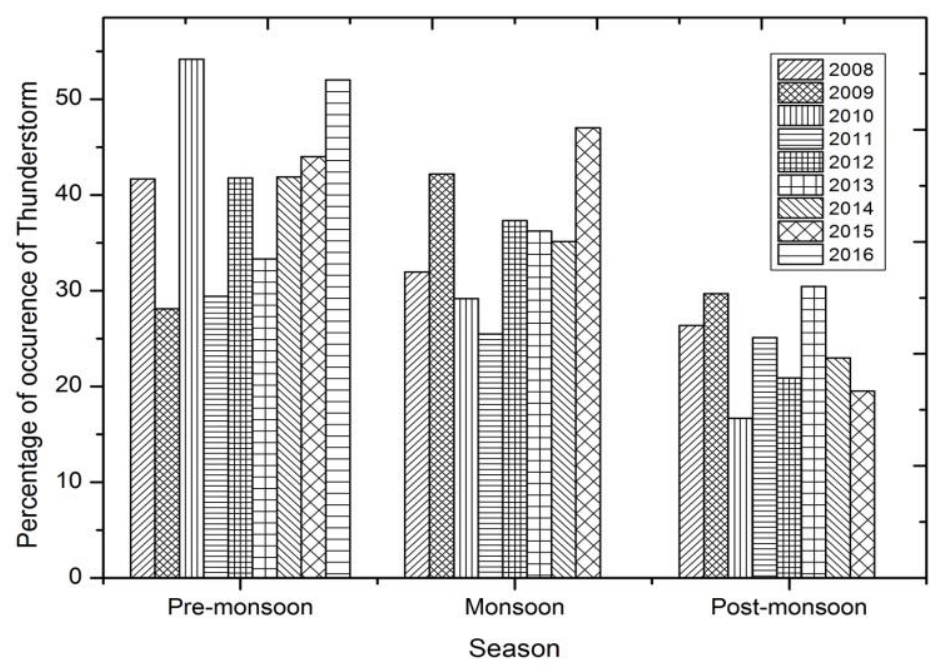

Figure 3: Eight years of seasonal thunderstorm occurrence pattern. Note gradual decrease of thunderstorm activity beyond pre monsoon season ( vernal equinoxial months). 
Based on this seasonal pattern, we will identify the precipitating sources for generation of thunderstorm events with special reference to vernal equinoxial months, an aspect which is dealt in the article 2.1.

\subsection{Possible Precipitation Sources leading to Thunderstorm at the NE region of India}

The NE region has a unique status from the rest of the country so far the precipitation and other climate related aspects are concerned and these characteristics are controlled by the number of wind flow sources to this region, especially during the months of March - May. There are at least three windows each having its own identical features, through which humid air enters to the region generating precipitation. Figures 4 (a, b, c d) show two such windows, one from west Asia and the other from the North east of China i.e., through Japan sea. Figure 4(e) represents precipitaion to the region through inflow of wet air from the third windiow i.e., from the Bay Of Bengal (BOB).

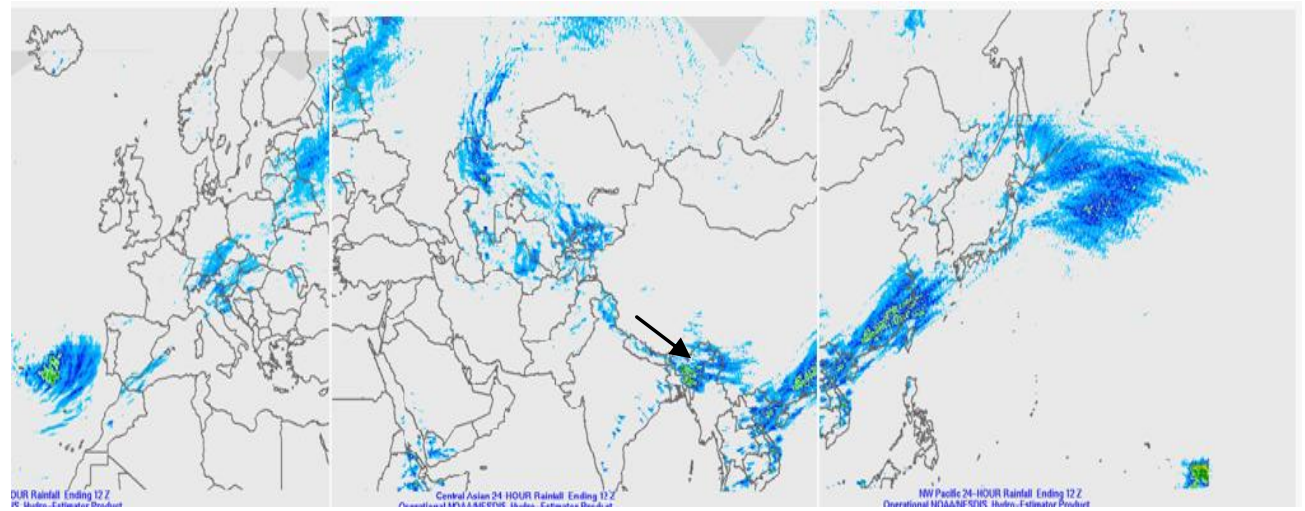

(a)

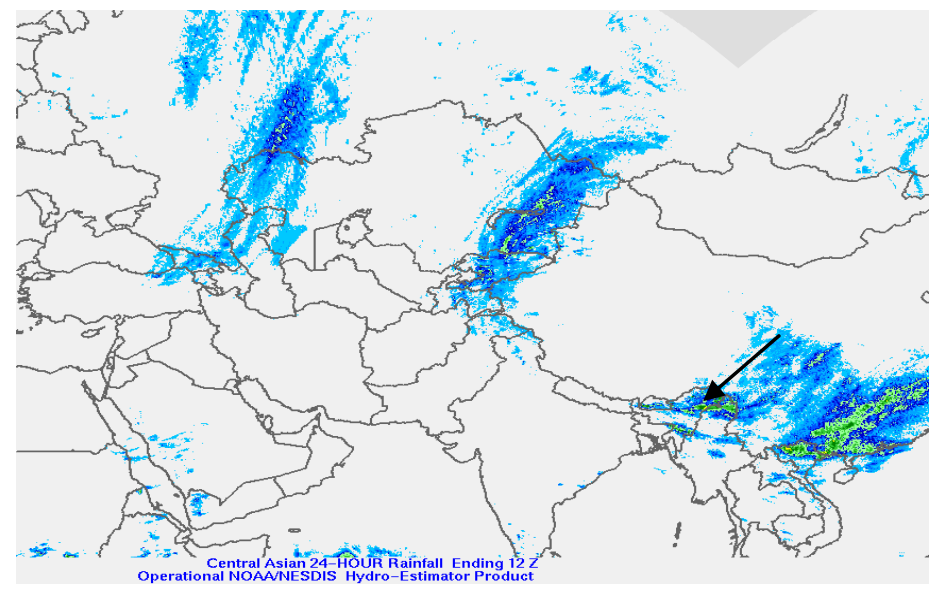

(b) 


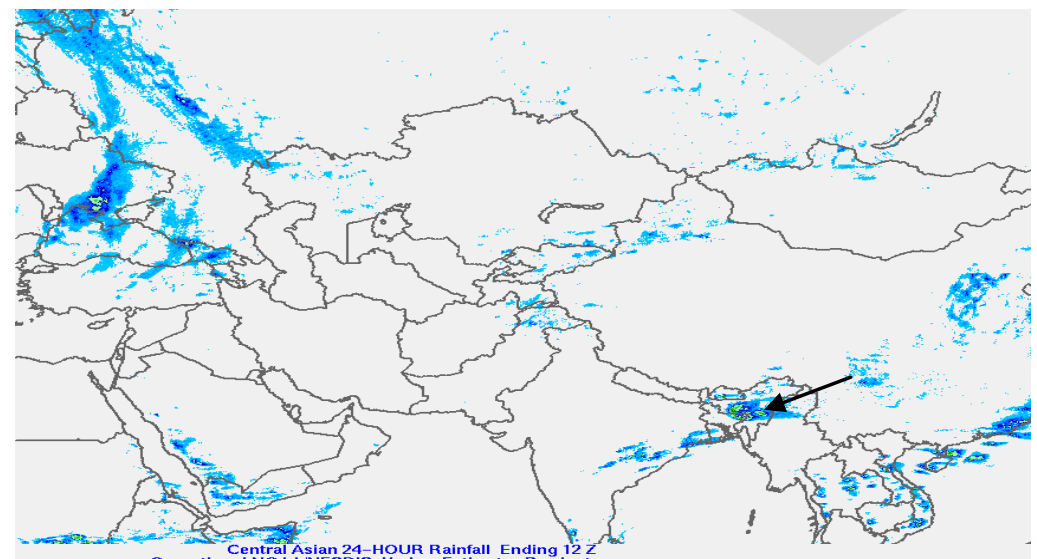

(c)

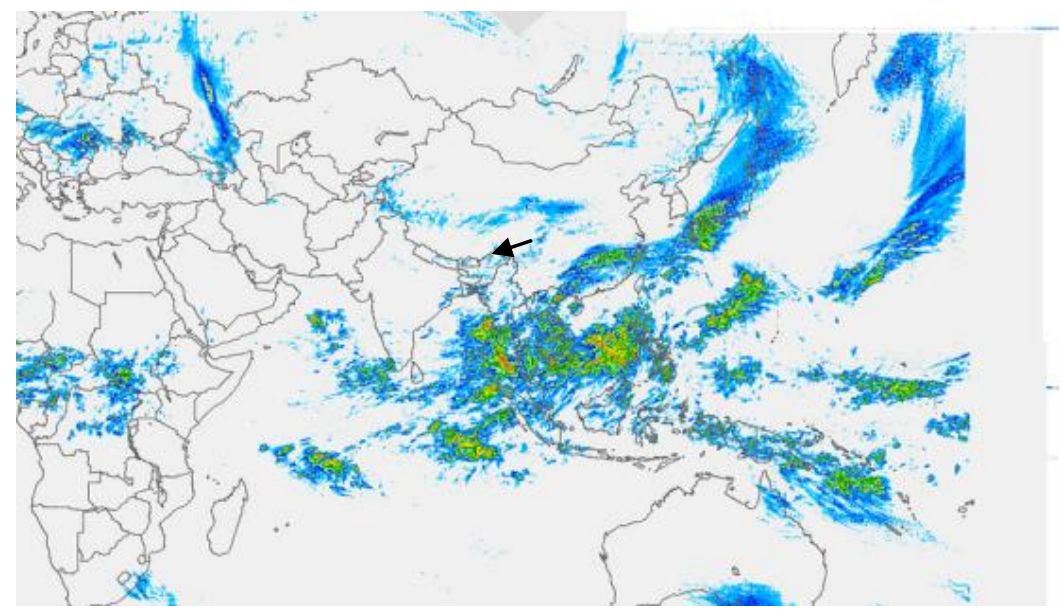

(d)

Figures 4(a,b, c,d) : Display the sources of precipitaion to the NE region during vernal equinoxial seasoins : (a) from Western Asia and eastern region of China, (b) though Japan sea, (c) from North east part of China and (d) from mid China.

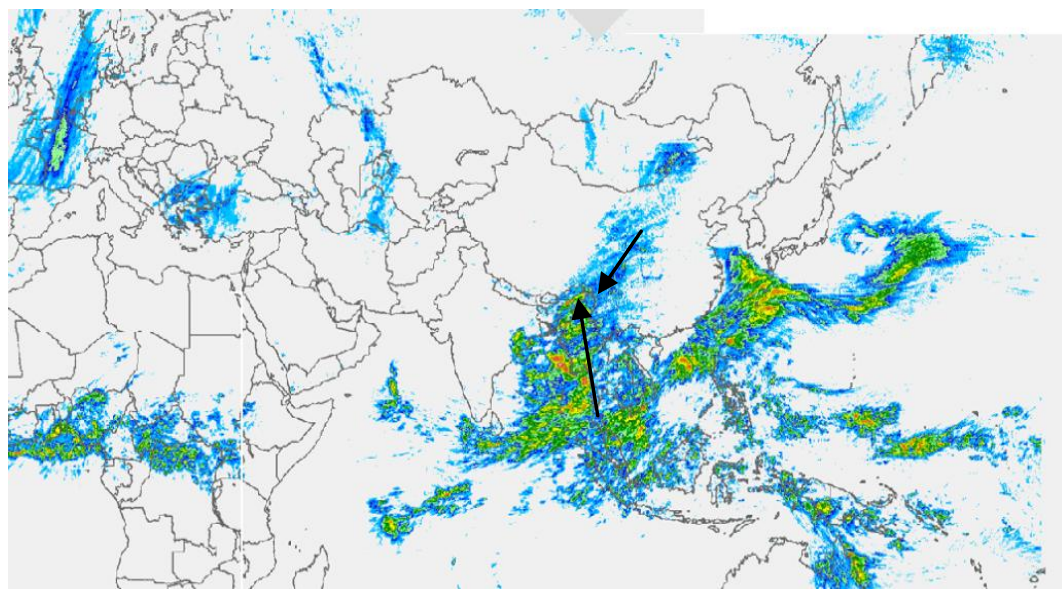

Figure 4e: Shows sources of precipitation to NE : Mid China and Bay of Bengal. 
These windows are mostly effective during vernal equinoxial months from mid -March to Mid -May, when rest of the continent undergoes a period of drought. However, with the onset of Monsoon in June, when the south westerly wind causes precipitation in almost half of the continent, the NE region has a relatively low rainfall status (Figure 5a, b). However, with the increase in Monoon strength, the NE states receive precipitation through the $\mathrm{BOB}$ route and no other window is active in this season.

Thus, during the thunderstorm period, the main sources of precipitation to the NE are from West Asia (China), BOB and a part from Japan Sea. This aspect will be examined in the article 3.0, to be followed. But, important also is to examine the contribution of aerosols in the growth of Cloud Condensation Nuclei $(\mathrm{CCN})$ and hence in generation of thunder clouds \& storms over the study environment.
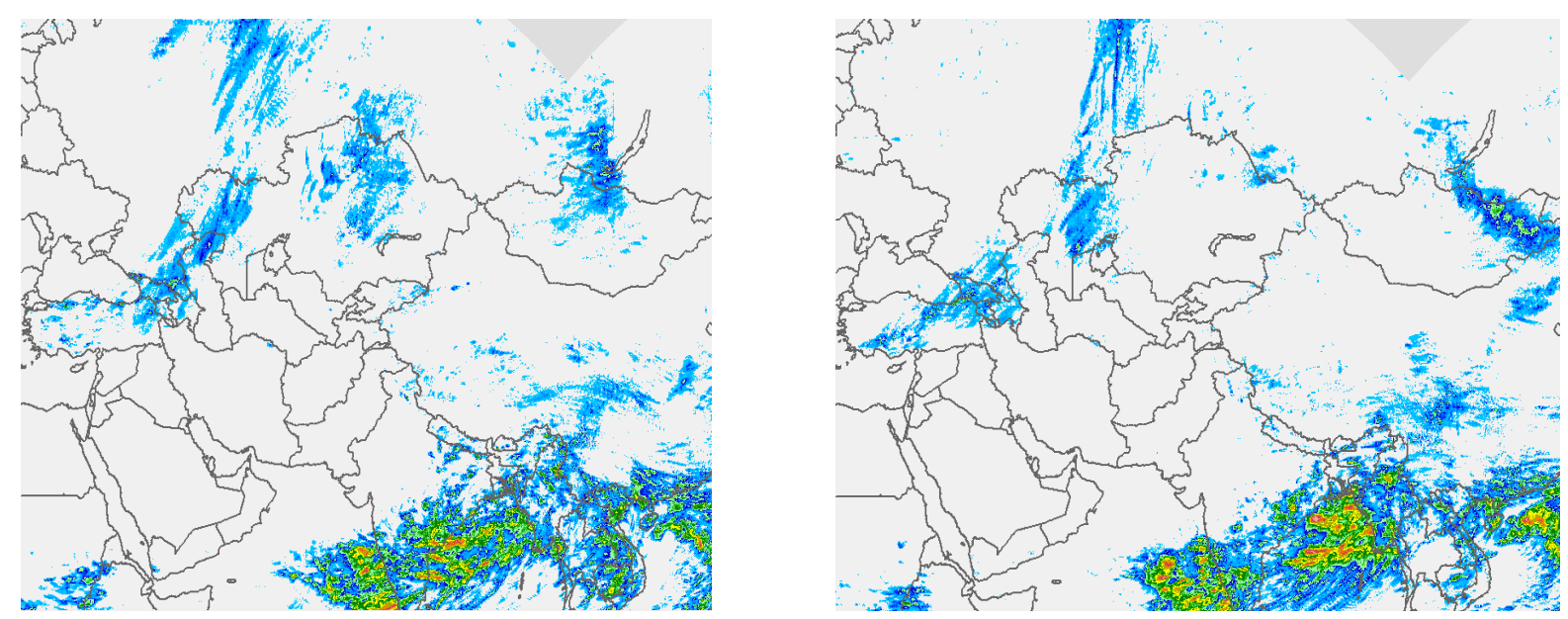

Figure 5(a,b): Onset of Monsoon season: note the major precipitaion source in india is through South Westerly wind. Also note the relatively low precipitaion in NE during this period.

\subsection{Aerosol characteristic features over NE region as trigger source for growth of thunderstorm:}

One of the processes between aerosol and cloud is through the nucleon well known as Cloud Condensation Nuclei (CCN) that assists in condensation of water vapor into cloud droplets .Thus, it is important to understand aerosol dynamics related to the growth of $\mathrm{CCN}$ associated with thunderstorm activity, along with the precipitation sources. It is also necessary to identify type of aerosols and their sizes as these properties of aerosols have great control on altitude at which precipitating cloud forms as well as in tracing their sources of origin. A few relevant aerosol features seen over Guwahati are presented below. 


\subsubsection{Observation of Aerosol features from MODIS \& LIDAR of GU:}

Starting with MODIS Aerosol Optical Depth (AOD) data, this article will finally present aerosol features seen over Guwahati with Micro pulse Lidar (MPL). Shown in Figure 6a, a few global AOD profiles for vernal equinoxial months, the season when thunder storm activity reaches its peak over the $\mathrm{NE}$ region. It is apparent from the AOD distribution features that during this season, there is transportation of aerosols from remote places as far as from west and mid China to this zone. But with the onset of Monsoon from (June to August), these windows are not active for aerosols to migrate to the NE region (Figure 7).
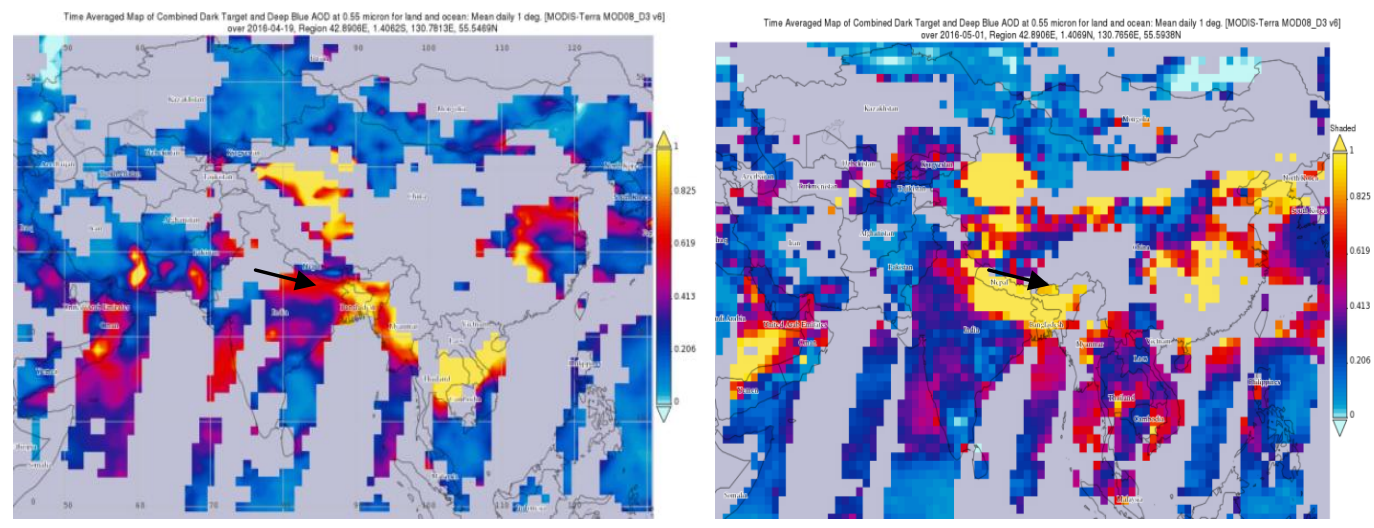

Figure 6: Shows transport of aerosol to NE from China during vernal equinoxial months.
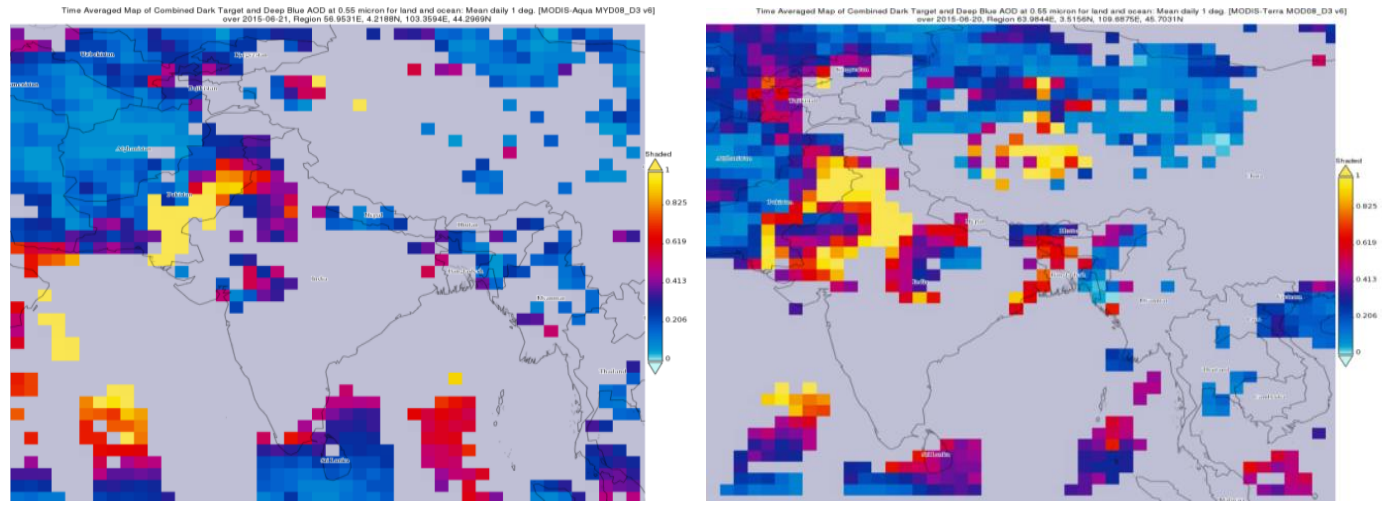

Figure 7: Note that aerosol flow to NE is absent with the onset of Monsoon season.

The analysis of 3- years of AOD data from 2012 to 2015 on the flow character of aerosol to the NE states from China, shows that more than $80 \%$ transportation of aerosols may occur to this region from China during vernal equinoxial season compared to other season say even for Autumnal equinoxial months (Figure 8). 


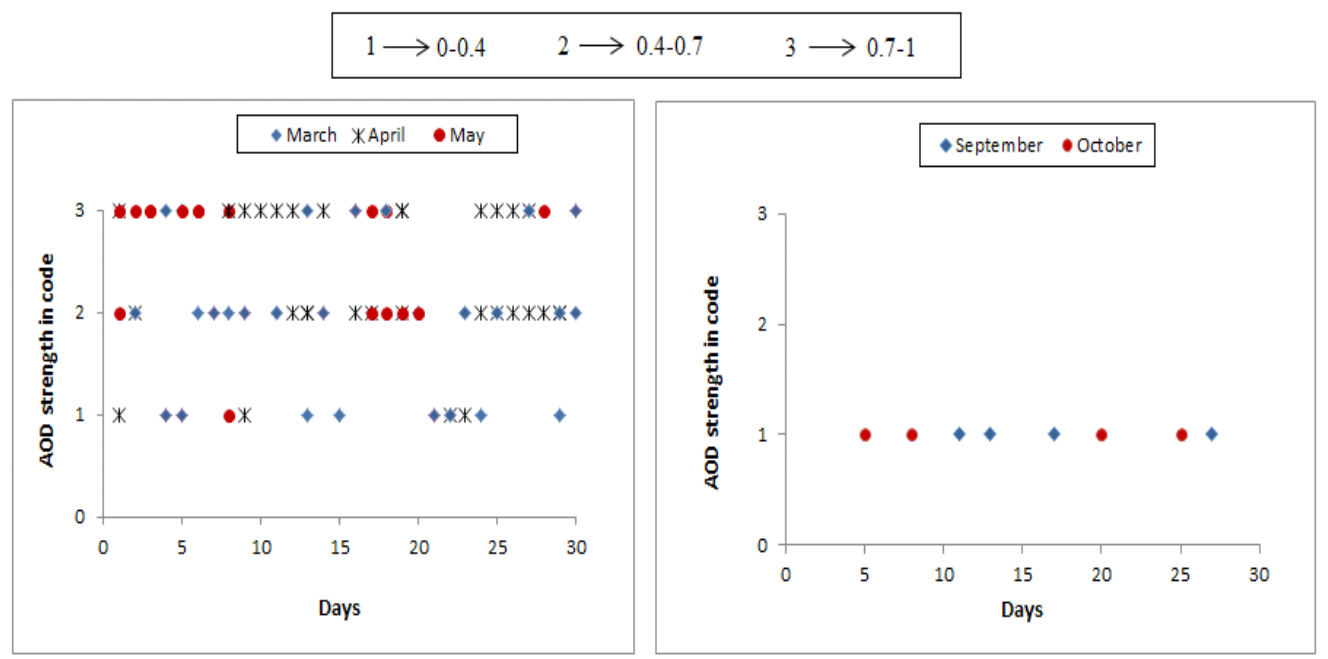

Figure 8. Note flow of aerosol with strong AOD from Western Asia to NE region during vernal equinoxial months . Conspicuous absence of the same is noted during other seasons; example shown for autumnal equinoxial period.

The abundant accumulation of aerosols during vernal equinoxial months as observed through MODIS data is also well detected by GU lidar [Baishya et al., 2001; Choudhury et al., 2012]. The presence of large aerosols from surface to $2 \mathrm{~km}-3 \mathrm{~km}$ altitude is one of the common features of the vernal equinoxial months over Guwahati. The MPL echograms of Figure 9, where aerosol counts are shown (a) for vernal equinoxial season and (b) for the autumnal months, clearly display the conspicuous differences of aerosol features between the two seasons. One can note that strong aerosol backscatter counts of vernal equinoxial months are absent in the autumnal months. Similar is the case for extinction coefficient of aerosol (Figure $.9 \mathrm{~b}$ ), the magnitude of which is much higher in April (a vernal equinoxial month) compared to aerosol- $\sigma$, of the autumnal equinoxial season. A long period of observation on aerosol extinction coefficient through MPL of GU also shows its significantly high value during vernal equinoxial months, a feature well focused in Figure 10 and Figure 11 where extinction coefficients of different seasons are presented. 

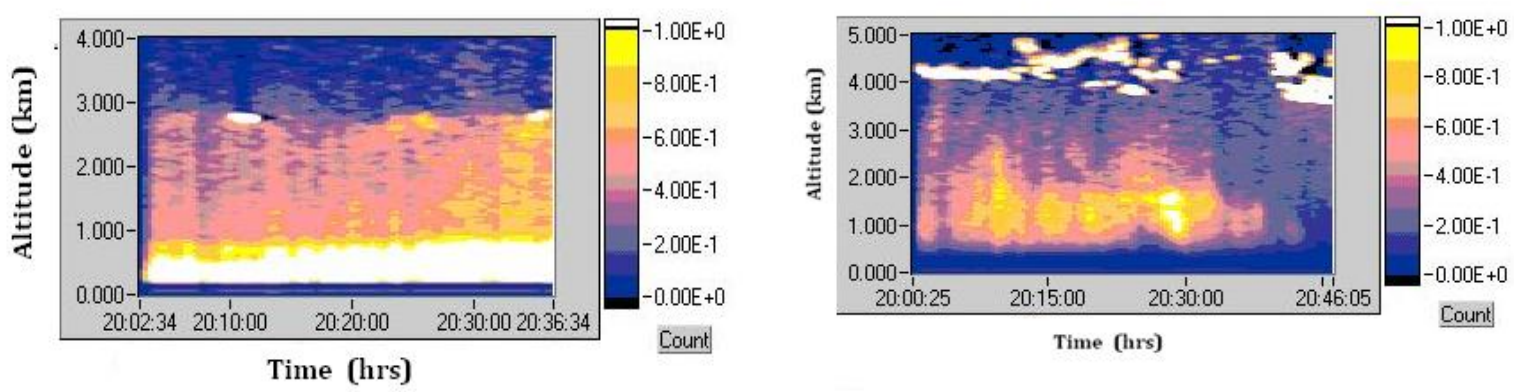

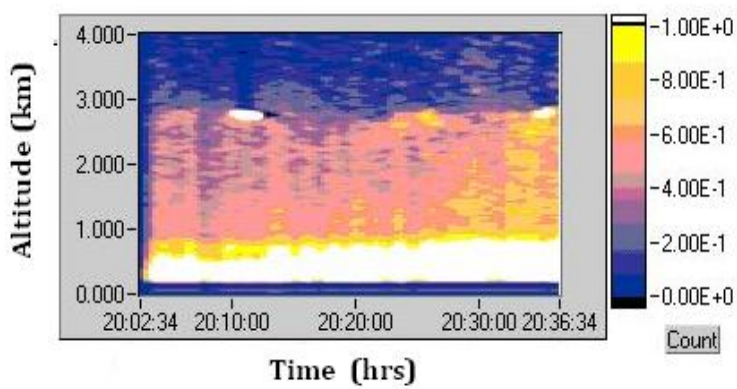

(a)

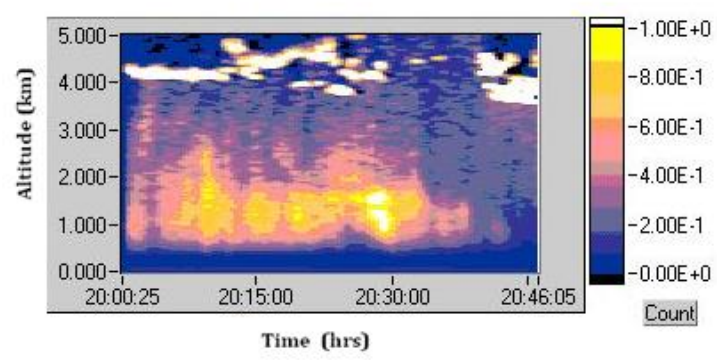

(b)

Figure 9 : Lidar echograms showing strong aerosol during (a) vernal months and relatively low counts of aerosols during

(b) autumnal season.
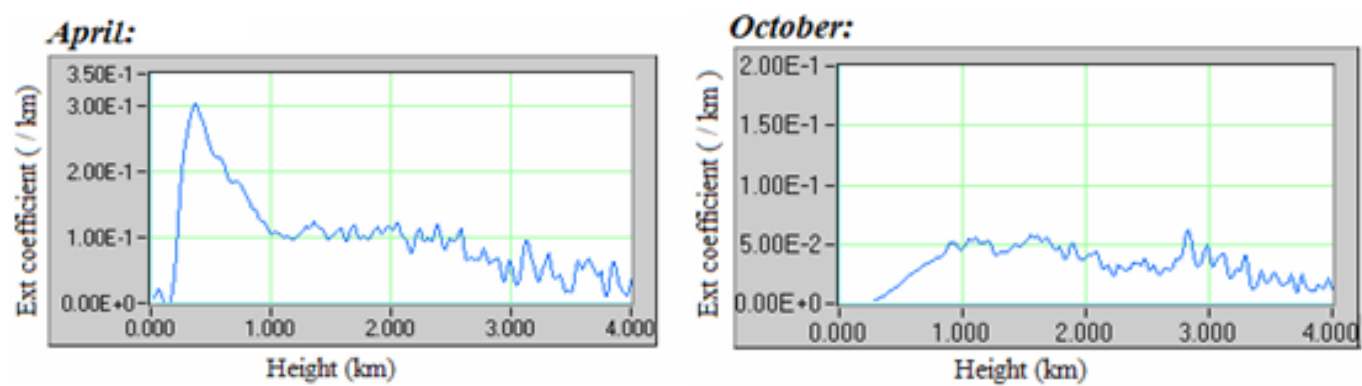

Figure 9 (b) Aerosol extinction coefficients: (a) Note strong values of extinction coefficient during (a) vernal months and (b) relatively weak values in autumnal season.

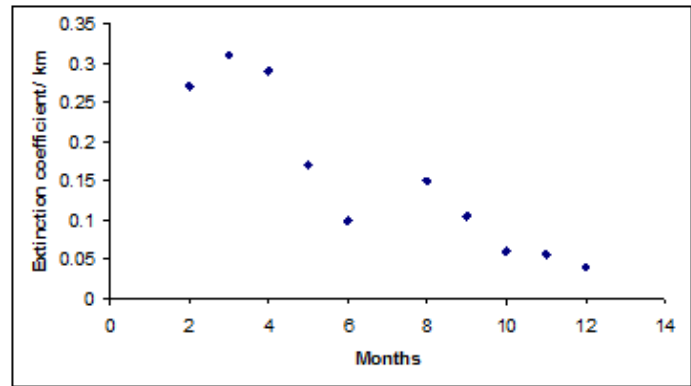

Figure 10: 2-years average value of extinction coefficient over Guwahati as observed by MPL lidar .Note strong values of extinction coefficient $(\sigma)$ during (a) vernal months and (b) relatively weak values in autumnal season. 


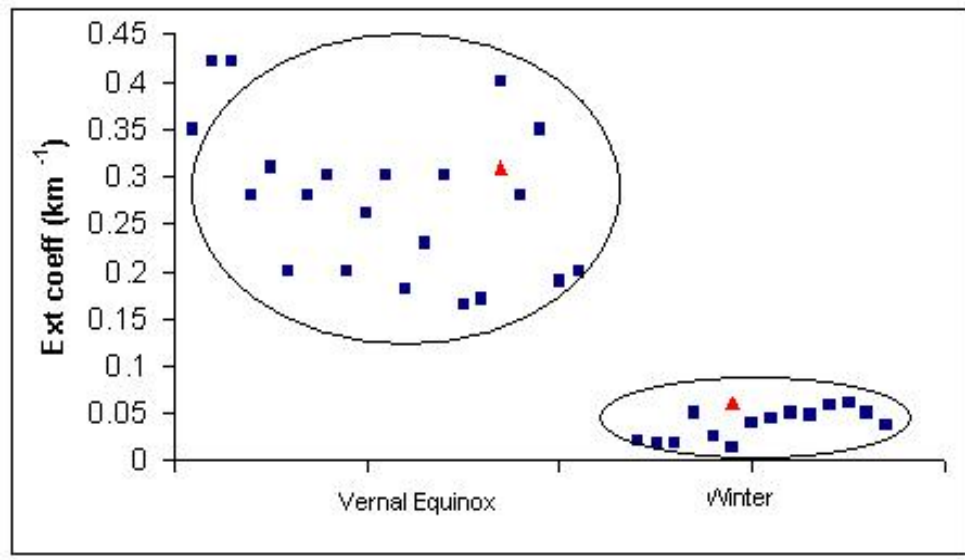

Figure 11: Monthly average value of extinction coefficient over Guwahati during vernal equinoxial months and in winter as observed by MPL lidar.

One of the possible sources leading to augmentation of aerosol concentration during vernal equinoxial season is by transportation of such particles to this region through flow of humid aerosol laden air from China, supported by the facts that accumulation of aerosol in the Sub-Himalayan range reaches maximum in this period of a year (Figure 4 and Figure 6). To examine possible transportation of such flow, the HYSPLIT back trajectory model is used that provides wind flow direction at defined atmospheric heights. Figure 12 presents one such example that shows possible track of aerosol to NE region through the western corridor suggesting that along with locally generated one , a component of aerosol is carried by westerly wind to the NE zone.
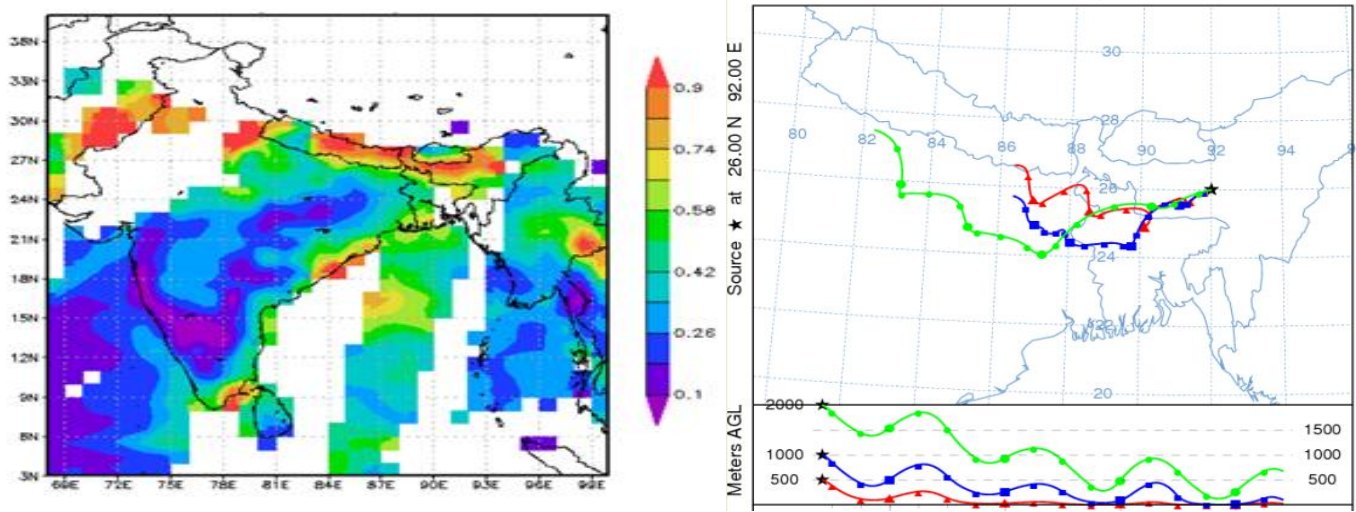

Figure 12 : Display (a) MODIS AOD data and (b) track of wind by Hyper SPLIT model . One can see large accumulation of aerosol layer in the Sub Himalayan range extended to NE region . Note the wind pattern, supporting migration from western Asia.

The analysis thus apparently supports that migration of aerosols took place to the study area from western Asia along with precipitating wind (of Figure 2a) although NE region receives a part of rain 
from Mid and East China (Figure 2c-d) also during this season (note the absence of accumulated aerosol in these paths). Therefore, most active window for transporting aerosol laden humid air to NE is by the western corridor. However one of the the most difficult problems here, is to identify the locally generated aerosols from those transported remotely.

One of the approaches is to examine the type of aerosols at different seasons of the year and then to look for differences if any in size distribution of aerosols in the Vernal equinoxial months ( most active thunder storm period) compared to other seasons of the year and finally to identify type of aerosols most abundant during thunderstorm season. In this approach one need to determine the size of aerosol particles, an aspect discussed in the following article.

\subsection{Need of the evaluation of Size of the aerosol particles:}

We have observed from AOD data that contribution of aerosols to total population in this region has strong components from remote sources and also that there is a significant role of aerosol on formation or inhibition of rain bearing cloud. However, these data do not provide size of aerosols. This is true also for the case of MPL data of aerosols where we get only backscatter and extinction coefficients as parameters but not size distribution of aerosol particles, due to inherent limitation of the system.
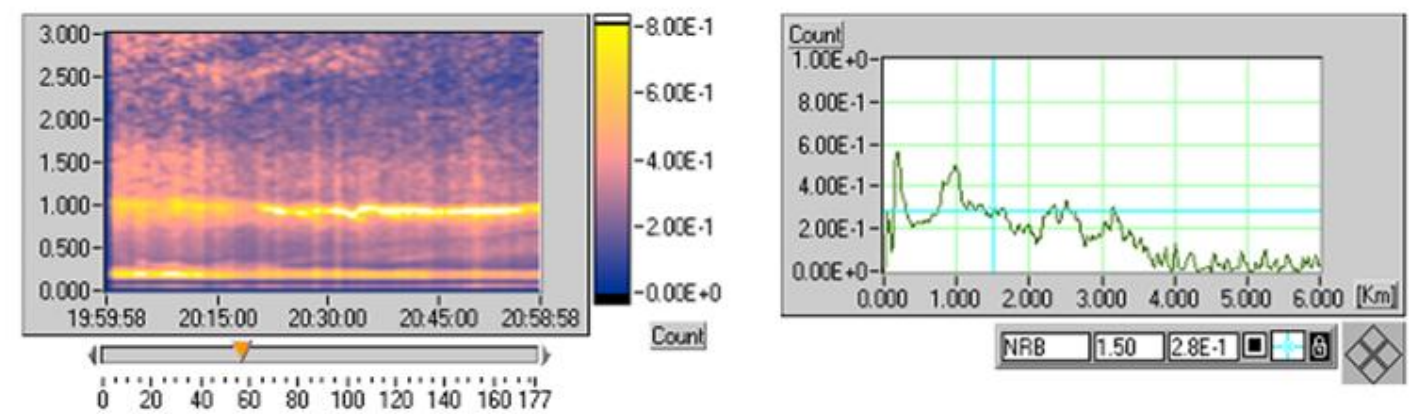

Figure 13 : LIDAR echogram over Guwahati shows (a) aerosol backscatter counts below ABL, trapped aerosol in ABL and aerosol above ABL; (b) Extinction coefficient $(\sigma)$ of aerosol :Note high values of extinction near surface, at $1 \mathrm{~km}$ (Trapped at ABL).

However, even with these shortcmings a few faeatures seen in the MPL echogarm support presences of mixed aerosls in vernal seasons over GU atmosphere. One such case is shown in Figure 13, where the differences in the basic backscatter and extinction coefficient features of aerosols below the Atmospheric Boundary Layer (ABL, at around $1 \mathrm{~km}$ ), above the ABL are well received. The ABL is that part of the troposphere which is directly influenced by the activity of the earth's surface and in this layer particles usually originate from local and/or regional emission sources. But, in free troposphere 
(above ABL), particles are often advected from long distances and may even be from other continents. Therefore, these particles are usually distinguishable from the boundary layer particles regarding their optical and microphysical properties. Even with such supportive features, the MPL echogram can never offer type of aerosols or size distribution of aerosol particles. A model approach is therefore adopted here for identifying the aerosol type through their size distribution modules, a discussion in this regard follows in the next article.

\subsection{Model evaluation of type of aerosols present in the GU study environment through lidar data of GU:}

The approach that will be presented here for identifying type of aerosols is by evaluating extinction coefficients of aerosols of different types starting from basic lidar equation.

It is well known that scattering processes between lidar transmitting $532 \mathrm{~nm}$ signal and aerosols are elastic in nature where no appreciable energy exchange takes place between the scatterer and the incident photons and it is in the Mie regime, in which scatterer is comparable to or larger than the transmitted wavelength. Therefore, in the model computation of the types of the aerosols one needs to evaluate the extinction coefficient $\sigma$ defined by equation 1, using Mie scattering theory [Bergstrom et al., 2007]

$$
\sigma=\int^{r_{2}} n^{\bmod }(r) \delta(r, \lambda) d(\log r) \ldots \ldots
$$

Where $\mathrm{n}^{\text {mod }}$ denotes the size distribution at the given radius $\mathrm{r}$ of the particle and $\sigma$ is the extinction cross section at particular wavelength for a given size. Thus it is seen from equation (1) that to calculate extinction coefficient it is essential to know

1) The size distribution of aerosols, $n^{\text {mod }}(r)$ and

2) The extinction cross-section, $\delta(r, \lambda)$

To calculate the above two parameter the following approaches are adopted keeping in mind the study area falls in a Sub- urban environment. Size distribution describes the number of particles of a certain radius, from a congregation of particles of different sizes. Depending upon location, atmospheric conditions and presence of local pollution sources their concentration changes [Bourdon, 1997]. A number of size distribution models for urban and rural situations are though available, there is practically no well developed model based on suburban conditions. Therefore, for obtaining number 
density over environment of our interest, we start by utilizing the urban and rural models with the size distribution parameters such as $\mathrm{N}_{\mathrm{i}}$, and $\mathrm{r}_{\mathrm{i}}$, in three different modes as defined in Table-1. In these models the particles are assumed to be spherical in size and are given for Urban and Rural environments. Size distribution describes the number of particles of a certain radius, from a congregation of particles of different size. Depending upon location, atmospheric conditions and presence of local pollution sources their concentration changes [Bourdon, 1997]. A number of size distribution models for urban and rural situations are though available, there are few models based on suburban conditions. Therefore for obtaining number density over environment of our interest, we start by utilizing the urban and rural models with the size distribution parameters (in three different modes) as defined in Table-1. In these models the particles are assumed to be spherical in size and are given for Urban and Rural environments.

Next, the size distribution parameters $\left[\mathrm{N}_{\mathrm{i}}, \mathrm{r}_{\mathrm{i}}\right]$ of Urban and Rural models from Table-1 are interpolated to receive values suitable for the sub Urban environment [Saikia , 2010]. Seven probable intermediate distributions modules are framed ( Table -2) between these two extreme environments to fit the status of NE region specially of Gauhati . The modules are farmed starting with $70 \%$ Urban and $30 \%$ Rural components to $10 \%$ Urban and $90 \%$ Rural values. Next, using appropriate values of $\mathrm{N}_{\mathrm{i}}, \mathrm{r}_{\mathrm{i}}$ and $\log \rho_{\mathrm{i}}$ from table II , for seven different modules at different rural and urban aerosol components $n^{\text {mod }}$ values are calculated by equation (2). The the remaining parameter for evaluation of the extinction coefficients (equation 1) is the extinction cross-section values at $532 \mathrm{~nm}$. For this purpose two approaches are adopted as discussed in the next article.

$$
n^{\bmod }=\sum_{i=1}^{3} \frac{N_{i}}{\log \rho_{i} \sqrt{2 \pi}} \exp \left[-\log \left(r / r_{i}\right)^{2} / 2\left(\log \rho_{i}\right)^{2}\right]
$$

In equation 2, $\mathrm{r}$ is the particle radius, $\mathrm{r}_{\mathrm{i}}$ is the mean radius, $\mathrm{N}_{\mathrm{i}}$ is the integral number concentration of the $\mathrm{i}$ th lognormal distribution function and $\rho_{i}$ is the geometric standard deviation.

\section{1 Determination of Extinction Cross section:}

The extinction cross-section depends on size of particle, the incident wavelength as well as on refractive index of the particle; hence determination of this parameter is highly critical. Here we take two methods, one by using extinction efficiency factor $Q_{e}$ [Bowmen et al., 1969] and the other by taking T-matrix approach [Brook et al., 1996]. For the former case, $Q_{e}$ is calculated from equation (3): 


$$
Q_{e}=\frac{\delta(r, \lambda)}{G} \ldots \ldots \ldots
$$

where $\mathrm{G}$ is the geometrical cross section of the particle is defined as(equation 4)

$$
G=\pi r^{2}
$$

As $\mathrm{Q}_{\mathrm{e}}$ depends on wavelength and radius $\mathrm{r}$, it is necessary to get the appropriate radius value for each $\lambda$ so that efficient Mie scattering condition ( $\mathrm{x} \sim 1)$ [Bergstrom et al., 2007] is maintained. This we have done by selecting $\mathrm{r}$ in such a way (for each $\lambda$ ) that $\mathrm{x} \sim 1$ in the following equation:

$$
x=\frac{2 \pi r}{\lambda}
$$

Inducting $\mathrm{Q}_{\mathrm{e}}$, from reported results [Lieu 2002; Lena et al., 2006] and $\mathrm{G}$ values calculated from equation 4, [with deduced radius of the particle through equation 5], the extinction crosection of the particle is calculated from equation (3) .

Next we adopt T-matrix approach for finding out extinction cross-section by taking our defined average size parameter for a relatively wide spectra of $\lambda$, to assess the reliability on the adaptation of the result for $532 \mathrm{~nm}$ MPL aerosol data. The T-matrix is a technique for computing extinction crosssection of homogeneous, arbitrary shaped particles based on the Lorentz-Mie theory [Mishchnko et al., 2002; Brook et al., 1996]. The important input parameters of the method are wavelength of incident light, real and imaginary part of refractive index of the scatterers, maximum and minimum radius of the scattering particles and the scattering angle. The real and imaginary parts of the RI are taken as 1.47 to 1.57 and 0.003 to 0.03 respectively for aerosols [Masayuki et al., 1983]. Through this technique we 


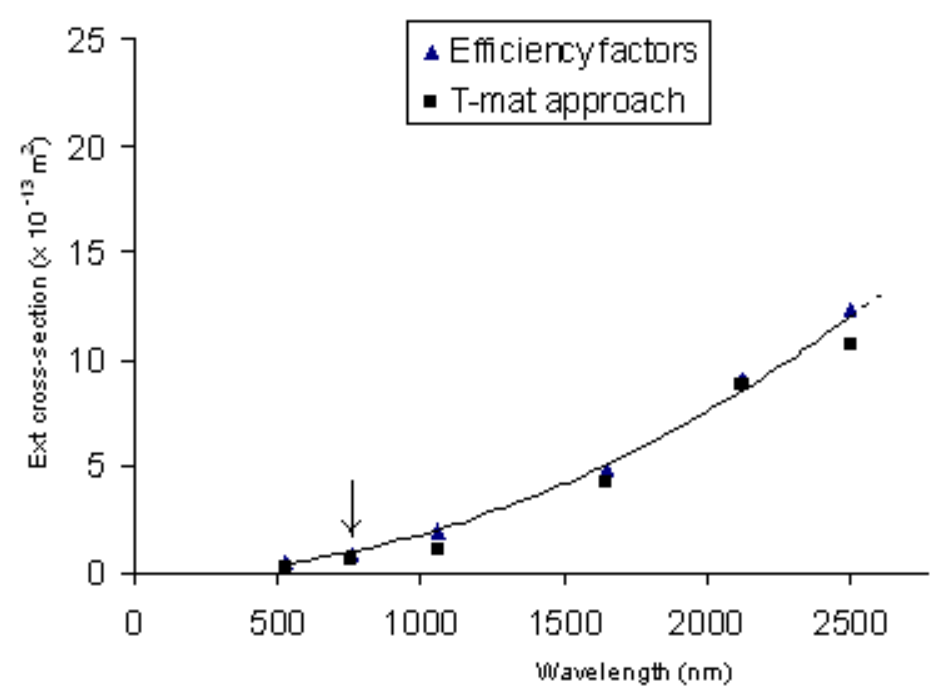

Figure 14: extinction cross-section of aerosols evaluated using the two approaches efficiency factor and Matrix approach, a step towards evaluation of extinction coefficient.

calculate extinction cross-section values $[\delta(r, \lambda)]$ for different wavelengths and then result so obtained is compared with those obtained using efficiency factor. The good correspondences of the extinction crossection values obtained by the two methods as displayed in Figure 14 , show reliablilty to adopt values of extinction crosection so obtained in our final evaluation of extinction coefficient magnitude $\sigma_{\text {ext }}$ at a defined $\lambda$. The $\sigma_{\text {ext }}$ values so calculated for modules of different contributions of rural and urban components are shown in the Table 3.

Table-1: Size distribution parameters of urban and rural models [Bhuyan et al, 2005; Bovensmann et al., 1999].

$\begin{array}{lllll}\text { Urban: } & \mathrm{i} & \mathrm{N}_{\mathrm{i}}\left(\mathrm{cm}^{-3}\right) & \mathrm{r}_{\mathrm{i}}(\mu \mathrm{m}) & \log \rho_{i} \\ & & & & \\ 1 & 2.120 \times 10^{6} & 0.006 & 0.240 \\ 2 & 3.7 \times 10^{4} & 0.031 & 0.297 \\ 3 & 4.9 & 0.540 & 0.328\end{array}$

Rural:

$\begin{array}{llll}1 & 1.00 \times 10^{3} & 0.008 & 0.20 \\ 2 & 8.00 \times 10^{2} & 0.034 & 0.32 \\ 3 & 0.72 & 0.460 & 0.34\end{array}$


Table-2: Size distribution parameters evaluated for intermediate composition of aerosols between urban and rural modules

\begin{tabular}{|c|c|c|c|}
\hline $\mathrm{i}$ & $\mathrm{N}_{\mathrm{i}}\left(\mathrm{cm}^{-3}\right)$ & $\mathrm{r}_{\mathrm{i}}(\mu \mathrm{m})$ & $\log \rho_{i}$ \\
\hline \multicolumn{4}{|c|}{ 1)70\% urban + $30 \%$ rural: } \\
\hline 1 & $1.484 \times 10^{6}$ & 0.0066 & 0.228 \\
\hline 2 & $2.614 \times 10^{4}$ & 0.0319 & 0.3039 \\
\hline 3 & 3.646 & 0.516 & 0.3316 \\
\hline \multicolumn{4}{|c|}{ 2) $60 \%$ urban $+40 \%$ rural: } \\
\hline 1 & $1.696 \times 10^{6}$ & 0.0068 & 0.224 \\
\hline 2 & $2.252 \times 10^{4}$ & 0.0316 & 0.3062 \\
\hline 3 & 3.228 & 0.508 & 0.3328 \\
\hline \multicolumn{4}{|c|}{ 3) $50 \%$ urban $+50 \%$ rural: } \\
\hline 1 & $1.0605 \times 10^{6}$ & 0.007 & 0.220 \\
\hline 2 & $1.89 \times 10^{4}$ & 0.0325 & 0.3085 \\
\hline 3 & 2.81 & 0.500 & 0.334 \\
\hline \multicolumn{4}{|c|}{ 4) $40 \%$ urban + $60 \%$ rural: } \\
\hline 1 & $8.486 \times 10^{5}$ & 0.0072 & 0.216 \\
\hline 2 & $1.528 \times 10^{4}$ & 0.0328 & 0.3108 \\
\hline 3 & 2.392 & 0.492 & 0.3352 \\
\hline \multicolumn{4}{|c|}{ 5) $30 \%$ urban $+70 \%$ rural: } \\
\hline 1 & $6.367 \times 10^{5}$ & 0.0074 & 0.212 \\
\hline 2 & $1.166 \times 10^{4}$ & 0.0331 & 0.3131 \\
\hline 3 & 1.974 & 0.484 & 0.3364 \\
\hline \multicolumn{4}{|c|}{ 6) $20 \%$ urban $+80 \%$ rural: } \\
\hline 1 & $4.248 \times 10^{5}$ & 0.0076 & 0.208 \\
\hline 2 & $8.04 \times 10^{3}$ & 0.0334 & 0.3154 \\
\hline 3 & 1.556 & 0.476 & 0.3376 \\
\hline \multicolumn{4}{|c|}{ 7) $10 \%$ urban + $90 \%$ rural: } \\
\hline 1 & $2.129 \times 10^{5}$ & 0.0078 & 0.204 \\
\hline 2 & $4.420 \times 10^{3}$ & 0.0337 & 0.3177 \\
\hline 3 & 1.138 & 0.468 & 0.3388 \\
\hline
\end{tabular}

On comparing the model evaluated extiction coefficient values $\left[\sigma_{\text {evaluated }}\right]$ with those obtained from experimental observations $[\sigma$ experimental $]$ at $0.532 \mu \mathrm{m}$ for five intermediate distributions,(Table - 3) one can note that in vernal equinoxial months aerosol is composed of equal constituents of Urban and Rural types ( marked within the box). This Urban -Rural aerosol composition status for different seasons are shown in Figure 15. 
Table-3: Model evaluated extinction coefficient values $[\sigma$ evaluated $]$ and those from experimental observations [ $\sigma$ experimental $]$ at $0.532 \mu \mathrm{m}$ for five intermediate distributions

\begin{tabular}{|c|c|c|c|c|c|}
\hline \multirow[t]{2}{*}{$\begin{array}{l}\text { Model } \\
\text { No. }\end{array}$} & \multirow{2}{*}{$\begin{array}{c}\text { Urban \& Rural } \\
\text { Contribution to } \\
\text { Distributions }\end{array}$} & \multicolumn{2}{|c|}{$\begin{array}{c}\sigma \text { at vernal equinox } \\
\left(\mathrm{km}^{-1}\right)\end{array}$} & \multicolumn{2}{|c|}{$\sigma$ at winter $\left(\mathrm{km}^{-1}\right)$} \\
\hline & & Expt. & Evaluated & Expt. & Evaluated \\
\hline 1 & Urban & & 0.539 & \multirow{9}{*}{0.05} & 0.423 \\
\hline 2 & $70: 30$ & & 0.416 & & 0.324 \\
\hline 3 & $60: 40$ & & 0.352 & & 0.276 \\
\hline 4 & $50: 50$ & 0.33 & 0.313 & & 0.246 \\
\hline 5 & $40: 60$ & & 0.259 & & 0.189 \\
\hline 6 & $30: 70$ & & 0.202 & & 0.158 \\
\hline 7 & $20: 80$ & & 0.142 & & 0.111 \\
\hline 8 & $10: 90$ & & 0.079 & & 0.062 \\
\hline 9 & Rural & & 0.0147 & & 0.0115 \\
\hline
\end{tabular}

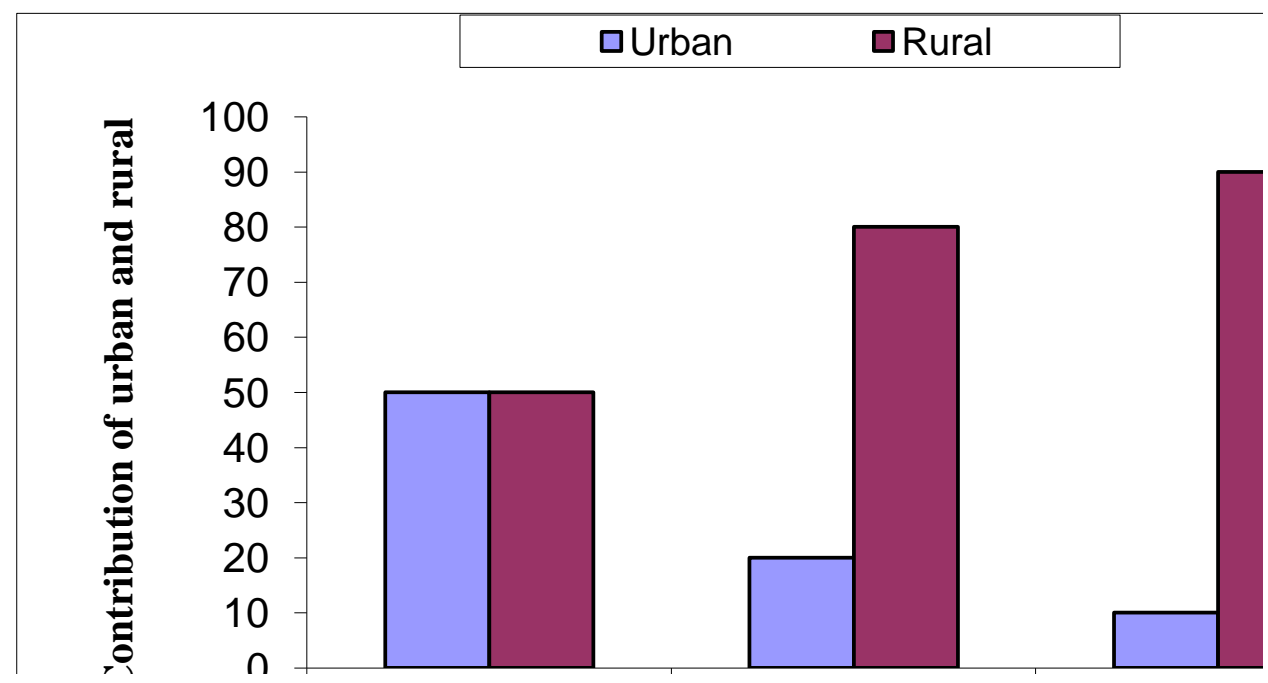

Figure 15 : Composition status of Urban and Rural aerosol status ; Not equal probability of mixing ratio of these two constituents during vernal months.

Such observation shows that only during vernal equinoxial months particles of small sizes ( Urban) are equally abundant with relatively large size of particles (Rural), indicating probability of producing $\mathrm{CCN}$ of smaller sizes are high compared to Autumnal and winter months. It is therefore important to 
identify the possible sources generating the composite aerosol constituents specially during vernal equinoxes, the period of our interest.

\subsection{Source Identification associated with growth of Thunderstorm:}

The lidar echograms over Guwahati and MODIS observations have already shown that migration of of aerosols from different sources to this region is possible. This observation goes along with model derived output which shows that during equinoxial months the aerosol is composed of (1) Urban and (2) Rural components with equal probability. These inputs suggest that during Vernal equinoxial season unlike the other months of a year, there are aerosols of different origins, which might be associated with growth of thunder storm activities . Therefore to identify the sources that may favour development of thunder storm during this vernal equinoxial season, the back trajectory model is adopted. The wind profiles received from the model show (Figure 16 a) that during thunder events two windows i.e., one in the west direction and other in south west corridor of the NE region are active for transporting aerosol laden precipitation from China and hot humid air from BOB . But during Non thunder days there is no transportation of aerosol to the zone through west window and there is flow of humid air from the BOB ( Figure 16b) only. The analysis suggests that aerosol is a significant component for triggering thunderstorm along with presence of hot humid air and required to be supported by the background environment.
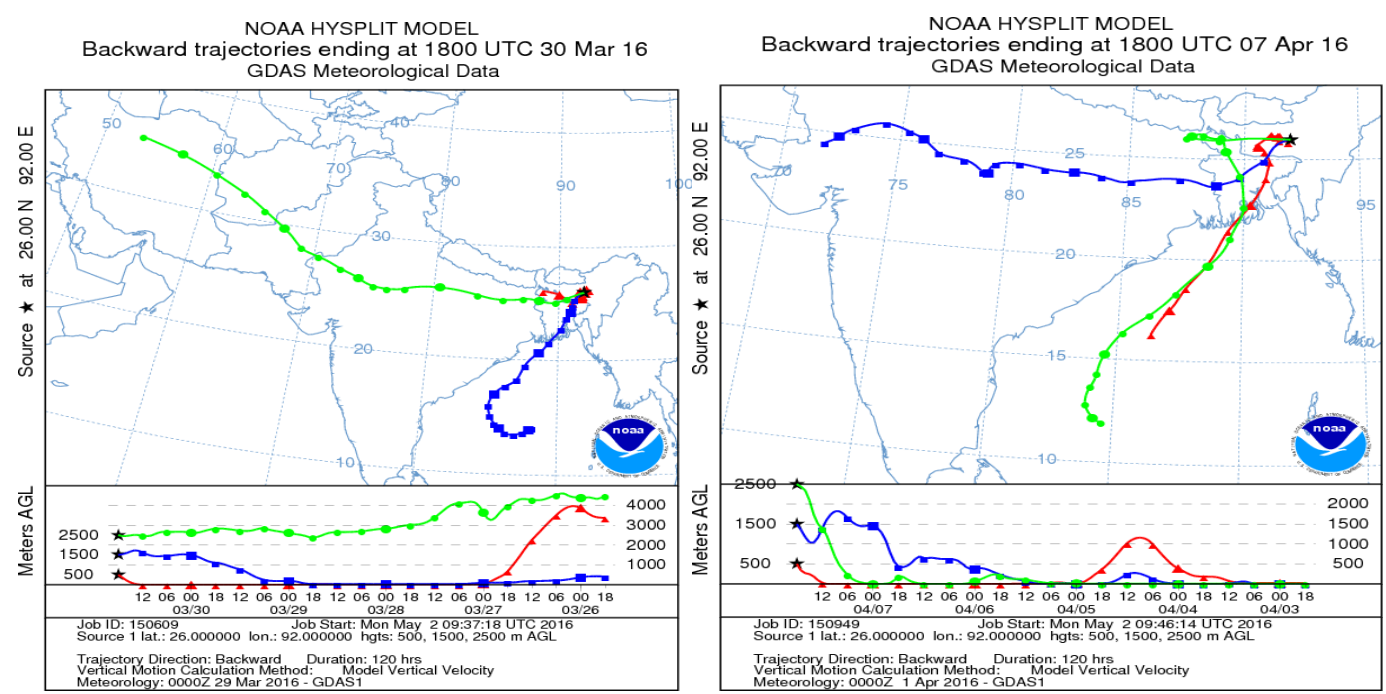


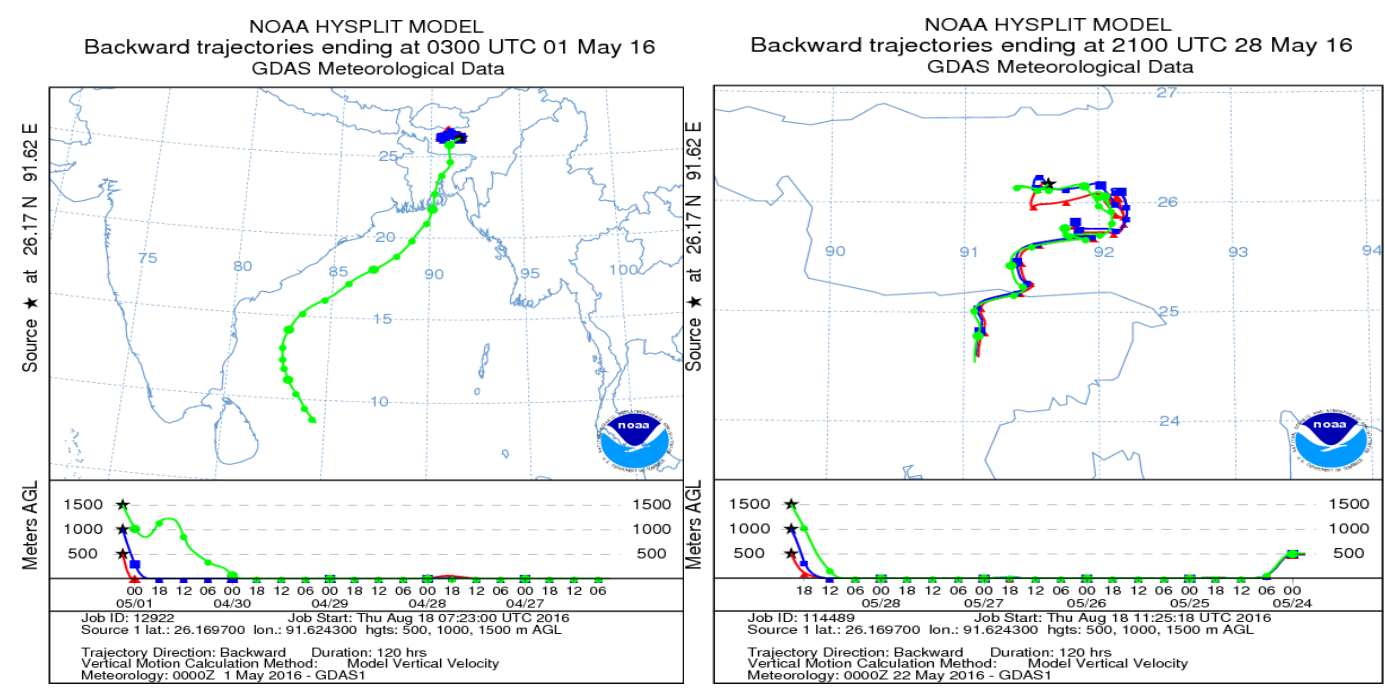

Figure 16 : Hyper split back trajectory model shows wind flow pattern to the NE region (a) during thunder days. Note there are two streams of in flows (i) from west carrying aerosol laden wet air, (west corridor, also note aerosol track of Figure 6) and (ii) from Bay of Bengal ( south west corridor) : (b) Note the absence of wind flow to the NE zone during Non thunder events.

\subsection{Discussions}

Development of high aerosol counts prior to formation of cloud structure leading to precipitation is an indirect evidence of aerosol -cloud relation reported by many earlier workers too [Burrows et al., 1995; Charlson et al., 1992; Chin et al., 2002; Devi et al; Weigelt et al., 2009; Twohy et al., 2002; Keil and Wendisch, 2001; Hegg et al., 1990; Radke and Hobbs, 1990]. These reports suggest that the enhanced photolysis caused by the vertical transport of precursor gases above the cloud, and presence of humidity in these regions, generate nucleation and hence high concentration of aerosol particles around the cloud. However, impact of aerosol on clouds and precipitation is a difficult sitiation to quantify because of their complex interactive processes [Chu et al., 2000; Clemesha, 1984; Forster et al., 2007; Stevens and Feingold, 2009]. Depending on their chemical composition and size, atmospheric aerosol particles can act as cloud condensation nuclei $(\mathrm{CCN})$ during cloud formation. Therefore, they determine the initial size distribution of the cloud droplets [Twomey, 1959; Coakley et al., 2002]. As a consequence, the aerosol particles have an influence on the optical properties and microphysical processes of clouds Amongst many aerosol types that make $\mathrm{CCN}$, soot or black carbon, sulfate and sulfur dioxide, dust particles, are a few to be taken note of, relevant to a semi urban environment like that of our study region. The efficiency of production of cloud droplets varies with size, composition and number density of aerosols. The population of CCN for a particular mode or size of aerosol is given by Eq. (6), 


$$
C C N=\sum \int_{D} n\left(D_{r}\right) d D_{r}
$$

Where $n\left(D_{r}\right)$ gives the size distribution of aerosol of any kind (or mode), with mean diameter $D_{r}$, a function of the chemical composition and is calculated for a specific maximum super saturation factor 'S', given by Eq. (7),

$$
D_{r}=\left(\frac{4 A^{3}}{27 B S^{2}}\right)^{1 / 3}
$$

Here, $\mathrm{B}$ is the mean hygroscopicity parameter for the chemical composition of the particles in a particular mode, A is the curvature parameter.

It is seen from Eqation (7) that super saturation decreases with size of the particle [Coakley et al., 2002] and therefore, it is important to know size of the aerosols that vary with local environment like rural, urban and maritime specially when thunder related aerosl types are to be assessed. We therefore calculate the number density of aerosol (equation 1) with sizes ranging from 1 micron to .0001 micron, taking two different Utrban and Rural composition modes [Cooney et al., 1968; Demoz et al., 2000; Devara et al., 2007]. The evaluated number densities for this semi-urban environment show that aerosol of size of 0.01 micron to 0.012 micron dominates in this season with sharp fall around and beyond the range and in the course spectra of particles; the number densities are equally available from 0.015 micron to 0.2 micron sizes. Mircea et al., [2002] and Devara et al., [2007], showed that increase of CCN number varies with aerosol type, enhancing in marine ambience with more aerosols population in coarse mode ( $>0.1$ micron), up to $97 \%$ in the rural case, and a maximum of $110 \%$ may be reached in the urban case when fine particles in range of 0.01 micron predominate, in presence of water-soluble aerosol organic compounds (WSOC). 


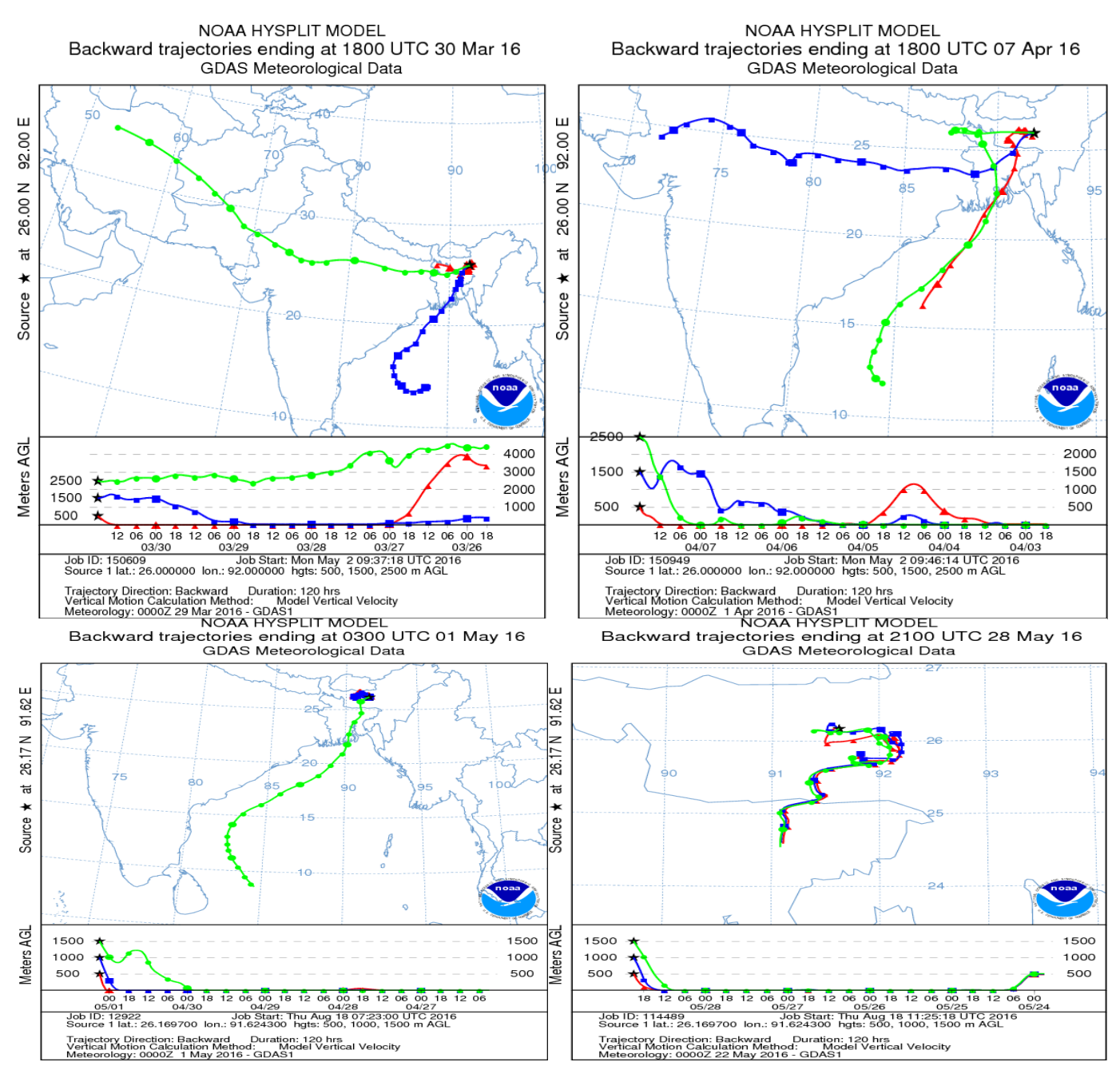

The distributions of " $n$ mod, at the two defined modes are calculated from Euation (1) for vernal equinoxial months and the model evaluated densities for semi-urban environment are presented in Figure 17. The situation in vernal equinox is therefore significant in this respect because of presence of equal number of Urban and Rural aerosol components. In a simple model assuming equal probability of presence of course (Rural ) and fine (Urban) components as in vernal season, one may expect the following precipitation status:

Referring back to the echogram of the vernal month (Figure 9 a, b) strong aerosols from near surface suggest presence of coarse particles (specially dust) of $\mathrm{SiO}_{2}$ based which are large in size and hydrophobic in nature with low probability of high, while beyond ABL low scattering from aerosols and low extinction coefficient value suggests along with $50 \%$ presence of Urban mode of aerosols i.e., weak extinction and weak backscatter profile shapes (are marks of finer aerosol signify that these are not 
$\mathrm{SiO}_{2}$ based and therefore composed of WSOC. (fine). Anthopogenic aerosols may increase or decrease precipitation by their radiative and $\mathrm{CCN}$ activities. It is also observed that tropical clouds with low CCN concentration may help precipitaion and high anthpogenic $\mathrm{CCN}$ concentration may discourage precipitaion by evaporating condensed water and also by reducing the drop sizes. This process may build up Convective Availble Poptential Energy (CAPE), leading to Thunderstorm.

\section{References}

Aspliden, C.I., A classification of the structure of the tropical atmosphere and related energy fluxes, J. Appl. Metor. 15, 692-697, 1976.

Baishya, R., Devi, M. \& Barbara, A. K., Software for lidar data analysis: development and application on MPL setup, Ind Jr. Radio and Space Phys., 32, 114, 2003.

Bergstrom R W, Pilewskie P, Russell P B et al, Spectral absorption properties of atmospheric aerosols, Atmos. Chem. Phys. Discuss., 1, 10669-10686, 2007.

Betts, A.K., Thermodynamic Classification of Tropical Convective Soundings, Mon. Wea. Rev. 102, 760-764, 1974.

Bhuyan P K, Gogoi M M and Moorthy K K, Spectral and temporal characteristics of aerosol optical depth over a wet tropical location in North East India; Adv. Space Res. 35, 1423-1429, 2005.

Bian, H., Chin, M., Rodriguez, J., Yu, H., Penner, J. E. \& Strahan, S., Sensitivity of aerosol optical thickness and aerosol direct radiative effect to relative humidity, Atmos. Chem. Phys, 9, 2375, 2009.

Bourdon A, Laser technique sniffs out pollutants; differential absorption lidar measures chemicals in the air over Athens, Photonics Spectra, 102-107, 1997.

Bowman M R, Gibson A J and Sandford M C W, Atmospheric Sodium measured by a Tuned Laser Radar, Nature, 221, 456-457, 1969.

Bovensmann H, Burrows J P, Buchwitz M, et al. SCIAMACHY - Mission objectives and measurement modes, J. Atmos. Sci., 56, 2, 127-150, 1999.

Brook E J, Sowers T and Orchardo J, Rapid Variations in Atmospheric Methane Concentration during the Past 110,000 Years, Science, 273, 1996. 
Burrows J P, Holzle E, Goede A P H, Visser H, Fricke W, SCIAMACHY - Scanning Imaging Absorption Spectrometer for Atmospheric Chartography, Acta Astronautica, 35(7), 1995, 445451.

Campbell, J.R., Dennis, L.H., Spinhirne, J.D., Scott,III, V.S. \& Turner, D.D., Operational processing and cloud boundary detection from Micro Pulse Lidar data, Presented in 19th International Laser Radar Conferences, 119, 1998.

Chaudhari, H.S., Sawaisarje, G.K., Ranalkar, M.R., Sen, P.N., Thunderstorm over a tropical Indian station, Minicoy: Role of vertical wind shear, J. Earth Syst. Sci. 119 (5), 603-615, 2010.

Chaudhury, A. K., Premonsoon thunderstorms in Assam, Tripura and Manipur. Indian J. Meteorol. Geophys., 12, 1, 33-36, 1961.

Chin M, Ginoux P, Kinne S, Torres O, Holben B N, Duncan B N, Martin R V, Logan J A, Higurashi A \& Nakajima T, Tropospheric Aerosol Optical thickness from the GOCART model and comparison with satellites and sun photometer measurements, J Atmos. Sciences, 1, 461474, 2002.

Chu X Z et al, Characteristics of Fe ablation trails observed during the 1998 Leonid Meteor Shower, Geophys. Res. Lett. 27, 1807-1810, 2000.

Charlson R J, Schwartz S E, Hales J M, Cess R D, Coakley J A, Hansen J E and Hofmann D J, Climate forcing by anthropogenic aerosols, Science, 255, 423-430, 1992.

Clothiaux, E.E., Mace, G.G., Ackerman, T.P., Kane, T.J., Spinhirne J.D \& Scott, V.S., An automated algorithm for detection of hydrometeor returns in micro pulse lidar data, J Atmos and Ocean Techn, 15, 1035, 1998.

Clemesha B R, Lidar studies of the alkali metals, MAP Handbook, 13, 99-112, 1984.

Coakley J A, Tahnk W R, Jayaraman A, Quinn P K, Devaux C and Tanre D, Aerosol optical depths and direct radiative forcing for ENDOEX derived from AVHRR: Theory, J. Geophys. Res., 107(D19), 8009, 2002.

Cooney J, Measurements on the Raman component of laser atmospheric backseatter, Appl. Phys. Lett., 12, 40-42, 1968.

Das Y., Some Aspects of Thunderstorm over India during Pre-Monsoon Season: A Preliminary Report-I, Journal of Geosciences and Geomatics Vol. 3, No. 3, 68-78, 2015.

Demoz B B, Starr D O'C, Whiteman D N, Evans K D and Hlavka D, Raman LIDAR detection of cloud base, Geophys. Res. Lett., 27, 13, 1899-1902, 2000.

Devi M. \& Barbara, A.K., Development of a Portable lidar, Ministry of Information Technology, India, final report, 2004. 
Devi, M., Barbara, A. K., Saikia, M. and Chen, W., Vertical distribution of optical parameter of aerosol by using portable atmospheric lidar system of Gauhati University, Ind. Jr. Radio \& Space Phys., 37(5), 333, 2008.

Devara P C S et al, Differential absorption lidar probing of atmospheric ozone over a tropical urban station in India, Meas. Sci. Technol. 18, 3, 639, 2007.

Forster, P., Ramaswamy, V., Artaxo, P., Berntsen, T., Betts, R., Fahey, D. W., Haywood, J., Lean, J., Lowe, D. C., Myhre, G., Nganga, J., Prinn, R., Raga, G., Schulz, M., and Van Dor5 land, R.: Changes in atmospheric constituents and in radiative forcing, in: Climate Change 2007: The Physical Science Basis. Contribution of Working Group I to the Fourth Assessment Report of the Intergovernmental Panel on Climate Change, edited by: Solomon, S., Qin, D., Manning, M., Chen, Z., Marquis, M., Averyt, K. B., Tignor, M., and Miller, H. L., Cambridge University Press, Cambridge, UK, New York, NY, USA, 2007.

Graß1, H., Albedo reduction and radiative heating of clouds by absorbing aerosol particles, Contributions Atmospheric Physics, 48, 199, 1975.

Hegg, D. A., Radke, L. F., and Hobbs, P. V., Particle production associated with marine clouds, J Geophys. Res. 95, 13917, 1990.

Hobbs, P.V., Aerosol cloud climate interactions, Academic Press Inc., New York, 1993.

Kessler, E. (ed), Thunderstorm morphology and dynamics, U.S. Department of commerce. National Oceanic and Atmospheric Administration, Environmental Research Laboratories, Vol $2,1982$.

Keil, A. and Wendisch, M., Bursts of Aitken mode and ultrafine particles observed at the top of continental boundary layer clouds, J. Aerosol Sci., 32, 649, 2001.

Kumar, G. and Mohapatra, M., Some climatological aspects of thunderstorms and squalls over Guwahati airport, Mausam, 57, 2, 231-240, 2006.

Koteswaram, P. and Srinivasan G., Thunderstorm over gangetic west Bengal in the premonsoon season and the synoptic factors favourable for their formation, Indian J. Meteorol. Geophys., 9, , 301-312, 1958.

Manohar G. K., Kandalgaonkar S.S., Tinmaker M. I. R., Thunderstorm activity over India and the Indian southwest, Journal of Geophysical Research ., vol. 104 ( D4), 4169-4188, 1999.

Markowski, P.M., Straka, J.M., Rasmussen, E.N., Direct Surface Thermodynamic Observations within the Rear-Flank Downdrafts of Nontornadic and Tornadic Supercells, Mon. Wea. Rev. 130, 1692-1721, 2002.

Mircea M, Facchni M C, Decesari S, Fuzzi D and Charlson R J, The influence of the organic aerosol component on CCN super saturation spectra for different aerosol types, TELLUS, 54 B , 74, 2002. 
Mukhopadhyay P., Sanjay, J., Singh, S.S., Objective forecast of thundery/non thundery days using conventional indices over three northeast Indian stations, Mausam 54(4), 867-880, 2003.

Radke, L. and Hobbs, P.: Humidity and particle fields around some small cumulus clouds, J. Atmos. Sci., 48, 1190, 1990.

Saikia, M. Measurement of Optical Properties of Aerosols and Methane concentration through Lidar and DIAL set up of Gauhati University, A PhD thesis, Gauhati University, Ch.4.

Sen, S.N., Mechanism of Bengal Tornadoes in the Nor'- wester Season, Nature 127, 128-129, 1931.

Spinhirne, J.D., Micro Pulse Lidar, IEE Transaction on Geoscience and Remote Sensing, 13, 48, 1993.

Spinhirne, J.D., Campbel, J.R. \& Dennis, L., Autonomous, fulltime cloud profiling at arm sites with Micro Pulse Lidar, Symposium on lidar atmospheric monitoring. (http://www.ams.confex.com/ams/annual2000/lidar/index.htm) 2000.

Stevens, B. \& Feingold, G., Untangling aerosol effects on clouds and precipitation in a buffered system, Nature, 461, 607, 2009.

Stokes G.M. \& Schwartz, S.E., The Atmospheric Radiation Measurement (ARM) Program: Program background and design of cloud and radiation test bed. Bull. Amer. Meteorol. Society, 75, 1201, 1994.

Twomey, S., The nuclei of natural clouds formation. Part II: The supersaturation in natural clouds and the variation of cloud droplet concentration, Pure Appl. Geophys., 43, 243, 1959.

Twohy, C. H., Clement, C. F., Gandrud, B. W., Weinheimer, A. J., Campos, T. L., Baumgardner, D., Brune, W. H., Faloona, I., Sachse, G. W., Vay, S. A., and Tan, D., Deep convection as a source of new particles in the midlatitude upper troposphere, J. Geophys. Res., 107(D21), 4560, 2002.

Tyagi, A., Thunderstorm climatology over Indian region. Mausam, 58(2), 189-212, 2007.

Weigelt, A., Hermann, M., Van Velthoven, P. F. J., Brenninkmeijer, C. A. M., Schlaf, G., Zahn, A., and Wiedensohler, A.: Influence of clouds on aerosol particle number concentrations in the upper troposphere, J. Geophys. Res., 114, D01204, 2009.

Whitby K T, The Physical characteristics of Sulfur Aerosols, Atmos. Environment, 12, 135, 1978.

Wulfmeyer, V and G. Feingold, On the relationship between relative humidity and particle backscattering coefficient in the marine boundary layer determined with differential absorption lidar, J. Geophys. Res., 105 (D4), 4729, 2000. 
Yabuki M, Kuze H, Kinjo $\mathrm{H}$ and Takeuchi N, Determination of Vertical Distributions of Aerosol Optical Parameters by Use of Multi-Wavelength Lidar Data, Jpn. J. Appl. Phys, 42, 686, 2003.

Yamane, Y., Hyashi, T., Evaluation of environmental conditionsfor the formation of severe local storms across the Indian subcontinent, Geophys. Res. Lett. 33, L17806, doi: 10.1029/2006GL026823, 2006. 